\title{
Microcantilevers and organic transistors: two promising classes of label-free biosensing devices which can be integrated in electronic circuits
}

\author{
Serafina Cotrone $\cdot$ Damiana Cafagna $\cdot$ Stefania Cometa $\cdot$ Elvira De Giglio $\cdot$ \\ Maria Magliulo $\cdot$ Luisa Torsi $\cdot$ Luigia Sabbatini
}

Received: 26 September 2011 /Revised: 22 November 2011 / Accepted: 24 November 2011 /Published online: 22 December 2011

(C) Springer-Verlag 2011

\begin{abstract}
Most of the success of electronic devices fabricated to actively interact with a biological environment relies on the proper choice of materials and efficient engineering of surfaces and interfaces. Organic materials have proved to be among the best candidates for this aim owing to many properties, such as the synthesis tunability, processing, softness and self-assembling ability, which allow them to form surfaces that are compatible with biological tissues. This review reports some research results obtained in the development of devices which exploit organic materials' properties in order to detect biologically significant molecules as well as to trigger/capture signals from the biological environment. Among the many investigated sensing devices, organic field-effect transistors (OFETs), organic electrochemical transistors (OECTs) and microcantilevers (MCLs) have been chosen. The main factors motivating this choice are their label-free detection approach, which is particularly important when addressing complex biological processes, as well as the possibility to integrate them in an electronic circuit. Particular attention is paid to the design and realization of biocompatible surfaces which can be employed in the recognition of pertinent molecules as well as to the research of new materials, both natural and inspired
\end{abstract}

Published in the special issue Surface Architectures for Analytical Purposes with guest editors Luigia Sabbatini and Luisa Torsi.

S. Cotrone $\cdot$ D. Cafagna $\cdot$ E. De Giglio $\cdot$ M. Magliulo $\cdot$

L. Torsi $(\bowtie) \cdot$ L. Sabbatini $(\bowtie)$

Department of Chemistry, University of Bari,

70126 Bari, Italy

e-mail: torsi@chimica.uniba.it

e-mail: sabba@chimica.uniba.it

S. Cometa

Department of Chemistry and Industrial Chemistry,

Pisa University,

56126 Pisa, Italy by nature, as a first approach to environmentally friendly electronics.

Keywords Organic field-effect transistors (OFETs) .

Organic electrochemical transistors (OECTs) .

Microcantilevers $\cdot$ Sensors $\cdot$ Biocompatibility

\section{Introduction}

In the design and development of surfaces and interfaces of devices aimed at the investigation of biological systems and processes, many issues are of great concern. Bio- and mechanical compatibility, biospecific recognition, signal transduction efficiency, chemical stability and topography have to be considered to achieve optimal integration with a biological environment. Among possible materials to interface with the biological world, organic materials (mainly conjugated oligomers/polymers, hydrogels) emerge as candidates owing to their unique properties. Their interfaces can be chemically tailored by simple synthetic approaches in order to meet the requirements of the biological environment; mechanical properties can be engineered so that hard vs. soft and gel materials can be obtained; incorporation of biomolecules easily builds up biological functionality into the organic (polymer) matrix and can tune properties such as biocompatibility and biorecognition. Bonding of bioreceptors can endow the material surfaces with highly selective capabilities; electrosynthesis may be exploited in the case of conducting polymers (CPs) in order to obtain films of controlled thickness coating electrodes of any shape and size. As to the class of $\mathrm{CPs}$, comprehensive critical reviews have been recently published which highlighted interesting applications in nanomedicine [1], in specific biological experiments [2,3] and in recording and eliciting signals in complex environments such 
as human neural systems [4]. In this last field very exciting investigations are demonstrating how polymer-coated microelectrodes can detect transmitter release from a single neural cell [5]. Particularly interesting is the recent approach to combine the benefits of both CPs and hydrogels in copolymers [6] to better meet the critical design requirements of neural interfaces.

The goal of new biosensor generation is the development of an inexpensive, portable and fully integrated single platform with ultrasensitive detection level, high selectivity and miniaturized sizes. Array configurations are often required for disease diagnosis and in general for the study of complex biological systems. In this respect, transducers that can be fabricated through standard integrated circuit production procedures as well as with complementary metal oxide semiconductor (CMOS) technology offer particular advantages [7].

This paper aims to review some recent results concerning the development of biosensing devices based on microcantilevers (MCLs) and organic transistors. These two apparently different classes of devices, besides having already shown quite a good level of performance as sensors [8-10], also have two quite relevant common features: label-free detection capabilities and the possibility to be integrated into a circuit. As to the MCLs, they can be readily fabricated from silicon wafers and other materials and integrated in sensing platforms known as micro- and nano-electromechanical systems (MEMS and NEMS). In particular, when referred to in biology or biomedical science, these devices are termed BioMEMS [11].

On the other hand, organic-based transistors can be fabricated as n- and p-type transistors which can be processed into complementary integrated circuits by using a recent but already quite mature organic electronic technology [12]. This technology also offers the advantage of being implementable on flexible substrates, including plastics, paper and fabrics.

MCLs represent a recent evolution of nanomechanical biosensors, offering several advantages over the conventional analytical techniques in terms of a tiny sensor area, a label-less detection method and a low analyte requirement. MCL technology arises from the atomic force microscopy (AFM) technique. AFM, introduced in the mid 1980s, is one of the most important analytical techniques in nanoscience. Today, AFM has gained revived interest as a transducer for its numerous imaging modes, such as topographical, electric potential, magnetic and force imaging $[13,14]$. As a natural succession to its application as a force transducer in AFM, MCLs were selected as a new platform for transduction in sensing technology more than a decade ago [15].

Organic-based transistors (OFETs and OECTs) have demonstrated great versatility in a wide range of applications including consumer electronics, photovoltaics and biotechnology [16]. Moreover, they are well suited for the development of devices to be interfaced with biological systems for many properties, among which their "soft" nature is of primary importance. In fact, they offer a good mechanical compatibility with both cells and flexible substrates making them also interesting for skin or body implantable sensors. As an example, an organic electronic ion pump (OEIP) was recently demonstrated to release neurotransmitters and stimulate cochlear cells in the inner ear of a guinea pig in vivo [17]. To achieve this aim the organic materials' biocompatibility and the preservation of the biological system's original function are of the utmost importance [18]. Since biological systems are based on cell-cell interactions and the transduction of biosignals between cells, the possibility to interface cells to organic materials to be integrated in electronic devices will be here reviewed.

Moreover, recent efforts made in exploring and testing unusual materials suitable for organic-based electronics to be integrated within advanced implantable biomedical devices will be reported. In particular, the fabrication of transistors made from biodegradable, bioresorbable, natural and natureinspired materials will be described [19-22].

\section{Organic field-effect transistors (OFETs) and electrochemical transistors (OECTs)}

OFETs and OECTs differ both in the structure and in the operating mechanism. The structures are reported in Figs. 1 and 2; more details can be found elsewhere [23, 24]. In OFETs the transduction mechanism is based on electrostatic gating consisting on a capacitive coupling between the organic semiconductor and the gate electrode [23]. On the other hand, the OECT operation relies on electrochemical doping/de-doping of an organic semiconductor film in contact with the electrolyte [24]. Although these devices have been extensively studied as chemical $[8,25]$ and biological sensors $[9,26,27]$, the possibility of interfacing them with living cells requires that the organic electronic material establishes a stable interface with water and conducts not only electronic but also ionic carriers. Life processes in fact take place in

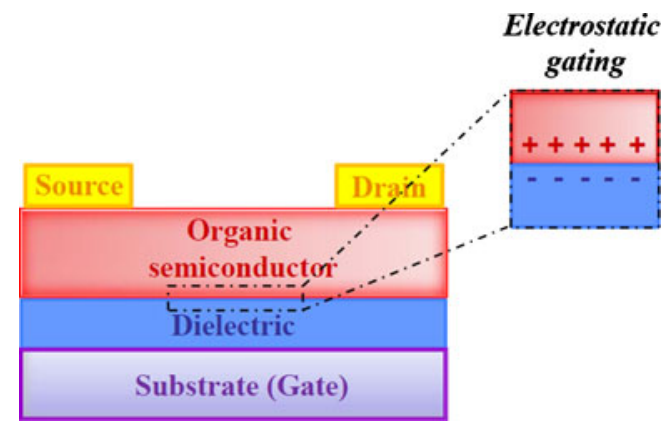

Fig. 1 Schematic of an OFET along with the relevant operating mechanism 


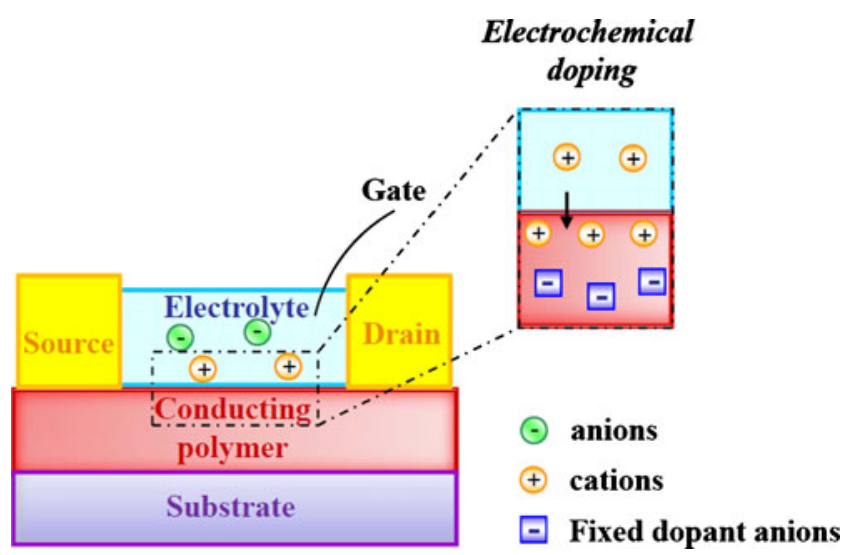

Fig. 2 Schematic of an OECT along with the relevant operating mechanism

aqueous media in which ions are carriers of information. Therefore, a material able to exchange ionic for electronic carriers, and vice versa, represents the ideal link between electronics and the world of biology.

\section{Organic field-effect transistors}

OFETs are three-terminal electronic devices composed of an organic semiconducting active layer, an insulating layer which is the dielectric, and three conductive terminals namely the source (S), drain (D) and gate (G). The source and drain electrodes can be fabricated on the top of the insulating layer or on the top of organic semiconductor. In the first case the OFET has a bottom contact device configuration, whereas in the second case a top contact device configuration (Fig. 1). During operation the capacitive coupling between the semiconductor layer and the gate electrode allows the current to flow between the source and drain terminals. This current can be controlled by modulating the electrical potential of the gate electrode [23].

Several examples of chemical and biological sensing [27, 28] by means of an OFET platform have been reported mainly addressing the possibility to perform a selective detection [29-31]. In this context a recent review [32] reports the many efforts spent on integrating bioactive transducing elements within the FET channel.

On the other hand, only few works demonstrated the possibility of OFETs operating in [33, 34] and detecting analytes in aqueous media $[35,36]$ because of organic material degradation and delamination when exposed to an aqueous environment [37, 38]. However, real-time detection of biological analytes requires stability for sensor operation in aqueous media. Analogously, to promote cell growth, proliferation and adhesion to the substrate, the stability of the organic semiconductors in the aqueous media is a critical issue. Besides this, the biocompatibility and biofunctionalization of organic semiconductors may be crucial points when organic materials interface with biological cells. Several parameters influence the biocompatibility of organic materials. Among these, one critical issue is that the solvents used to process organic materials (chloroform, xylene, toluene, chlorobenzene, or tetrahydrofuran) are usually toxic to living cells and the presence of their residues during the cell growth incubation step can affect their growth. Other important factors involved in cell adhesion, growth and proliferation are surface topography of the substrate [39-41], surface pattern and periodicity [42, 43], roughness [44-46], the oxidative state [47] etc.

In this respect, recently Biscarini and co-workers demonstrated that by controlling the layer morphology, the molecular orientation and the packing of the pentacene film it was possible to allow for the growth of neuronal networks on it [48]. The pentacene organic semiconductor was morphologically stable upon prolonged contact with physiological buffer and cell culture media thus allowing the adhesion of neural stem cells which remain viable on it for at least 15 days [48]. Moreover the processing of pentacene by high-vacuum sublimation was highly compatible with sterility standards. The possibility to integrate living neural cells into pentacene organic semiconductor thin films is an important step towards the development of bio-organic electronic transducers of cellular signals from neural networks.

Analogously Scarpa et al. demonstrated that by performing protein-based coatings and oxygen-plasma treatments on the surface of the spin-coated poly(3-hexylthiophene) (P3HT) organic semiconductor, the growth of mouse fibroblasts was enabled [49]. Moreover, the P3HT-based OFETs have been demonstrated to operate at low voltages [50] in water and complex media [51], hence opening new possibilities in the realization of a testing platform useful for cell analysis.

\section{Organic electrochemical transistors}

OECTs, described for the first time by Wrighton in the 1980s [52], consist of a conducting/semiconducting organic film in contact with an electrolyte (Fig. 2). The gate electrode is immersed in the electrolyte and controls the doping level of the conducting polymer. As a result of oxidative stability and increased conductivity, the poly(3,4-ethylenedioxythiophene) (PEDOT) doped with polyanions like poly(styrene sulfonate) (PSS) or $p$-toluenesulfonate (TOS) has become very popular in various bioapplications. The large anions (PSS or TOS) in PEDOT-based OECTs compensate the hole in the p-type organic semiconductor. Under the application of a positive gate bias, cations from the electrolyte enter the polymer film and compensate the large anions, thus decreasing the hole density in PEDOT. Therefore, OECTs provide a means to convert an ionic current into an electronic one efficiently $[53,54]$ and are thus very promising for interfacing electronics to biological systems. In addition, doped PEDOT showed 
good stability in aqueous solutions over extended periods of time [55] and little or no toxicity to a broad array of cell types, including endothelial cells, epithelial cells, fibroblasts, T cells and neuronal cells $[2,18]$. The PEDOT high biocompatibility also allowed the study of cell-cell interactions $[56,57]$ such as mechanisms involved in cell signalling $[5,58]$.

Recently, Berggren's group demonstrated that by integrating the PEDOT:TOS in an OECT it is possible to control the adhesion and the proliferation of cells by using the electrochemical gradient established along the transistor channel [59]. More interestingly Yang's group reported a disposable cell-based biosensor OECT for monitoring the cell activities in vitro [60]. As shown in Fig. 3a, the OECT device consists of a glass substrate covered with a PEDOT: PSS active layer on whose surface cancer cell line KYSE30 was grown directly in the culture medium. The OECT was tested in the presence of retinoic acid, an anticancer drug, which causes the rupture of the cancer cells inducing a change of the cells' surface charge [61]. Figure 3b reports the transfer characteristics of the OECT device integrated with cancer cell lines measured before (curve a) and after the exposure to retinoic acid for $1 \mathrm{~h}$ (curve b) and $7 \mathrm{~h}$ (curve c). As can be observed, there is a pronounced horizontal shift of the transfer curves when retinoic acid is added. This effect was not observed when retinoic acid was added to the OECT device without cells (Fig. 3c), thus demonstrating that the shift of the transfer curve is ascribable to the morphological and surface charge change of the adherent cells on the PEDOT:PSS layer rather than a change in the OECT capacitance.

New materials for bio-organic electronics

Recent advancements and "cross-fertilization" between the biomaterials field and organic electronics were very promising for the development of electronic devices for potential use in biomedical and clinical applications. In this context stability of the materials may be an important issue to be addressed, depending on the device utilization. As mentioned above, many organic materials used as the active layer in OFETs are susceptible to oxidation and loss of function if exposed to harsh conditions such as aqueous and high-salinity environments [33]. To overcome this drawback, new materials were found that are able to operate stably in hydrated or oxidative environments [36], thus allowing to interface electronics to the world of biology for biosensing applications [32] as well as for rapid screening of biological samples and point-of-care diagnostics [26]. On the other hand, in the case of advanced implantable biomedical devices and drug-delivery systems, where resorbability in the body after a desired time is required, particular attention is devoted to the development of biodegradable materials. A first step towards a biodegradable and
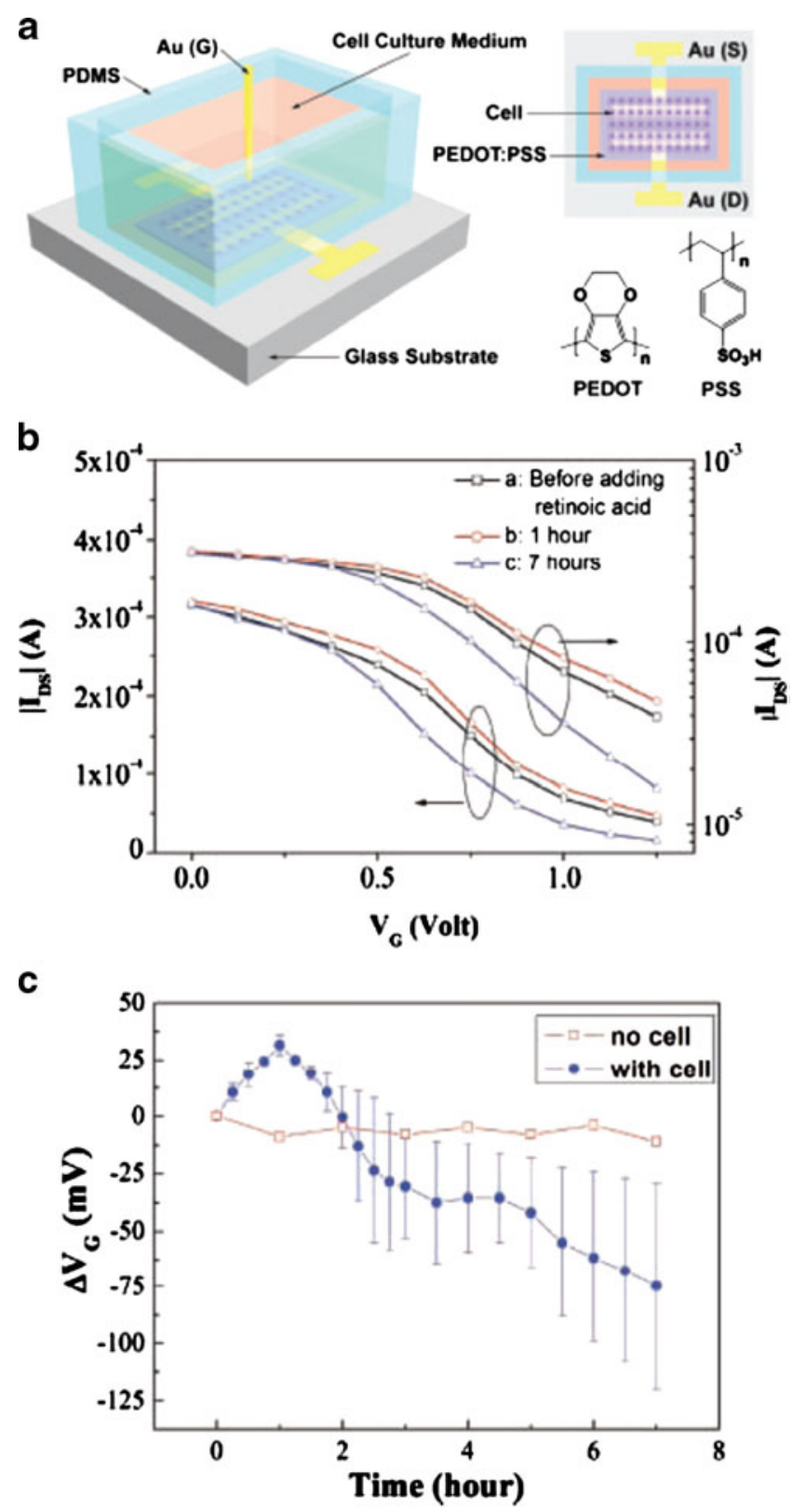

Fig. 3 a PEDOT:PSS-based OECT integrated biological cells. Cell culture medium was used as an electrolyte during the electrical measurements. b Transfer characteristics of an OECT device integrated with cancer cell lines measured before (curve $a$ ) and $1 \mathrm{~h}($ curve $b)$ and $7 \mathrm{~h}$ (curve c) after addition of retinoic acid. $\mathbf{c}$ Shift of the gate voltage of OECT devices for different periods of time after the addition of retinoic acid with (blue line) and without (red line) cancer cell lines on the top. Error bars show the standard error for several different samples [60]

biocompatible electronic device was reported recently by Bettinger and Bao [22] for potential use in temporary, electrically active medical devices. They developed a FET having poly(L-lactide-co-glycolide) (PLGA) as a degradable substrate constituting $99.89 \%$ of the total mass of the device, the water-soluble polyvinyl alcohol (PVA) as the gate dielectric and 5,5'-bis-(7-dodecyl-9H-fluoren-2-yl)-2,2'bithiophene (DDFTTF) as the organic semiconductor. 
DDFTTF is a small-molecule p-channel semiconductor which decomposes in a similar manner to melanin [62], whereas PLGA and PVA are commonly used for drugdelivery systems [63, 64] and biomedical applications [65], respectively. In addition, the conducting metals for electric contacts (silver for gate electrode and gold for source and drain ones) were chosen as they exhibit biocompatible properties suitable for use in medical devices [66, 67]. These devices showed a stable operation after exposure to water and the unique property of being resorbable as demonstrated through in vitro degradation studies.
Recently Bauer's group proposed new biodegradable, biocompatible, bioresorbable and even metabolizable materials for useful application in biomedical implants [19-21]. They described a bottom-gate, top-contact OFET realized using "exotic" materials based on natural materials or those inspired by nature (Fig. 4a). They used unusual metabolizable substrates like Ecoflex (from potato and corn starch), hard gelatine capsules (from pork skin and bones) and caramelized glucose (Fig. 4c) whose surface is often coated with a smoothing layer, rosolic acid (Fig. 4b), widely employed in medical and pharmacological fields [68, 69].

(a) OFET Schematic

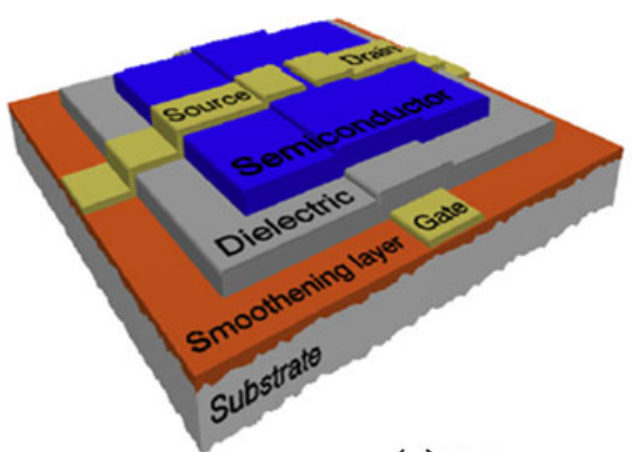

(b) Smootheners

(c) Substrates

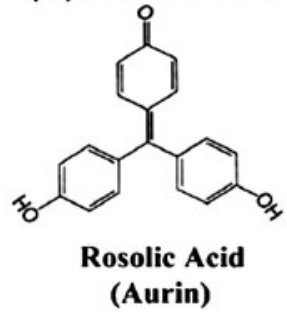

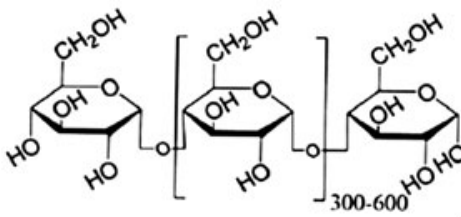

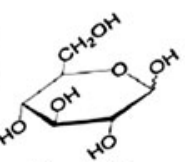

Ecoflex (Starch)

Caramelized Glucose Hard Gelatine (Collagen)

(d) Dieletrics

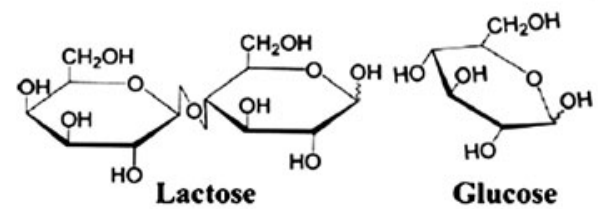<smiles>CCC(C)C(C)O</smiles><smiles>Nc1ncnc2[nH]cnc12</smiles><smiles>Cc1c[nH]c(=O)[nH]c1=O</smiles><smiles>Nc1cc[nH]c(=O)n1</smiles>

(e) Semiconductors

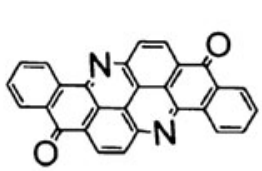

Vat Yellow 1

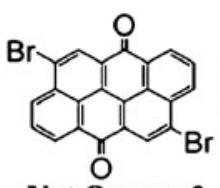

Vat Orange 3<smiles>OC1NC2CCCC2C1C1NC2CCCC2C1O</smiles>

Indigo

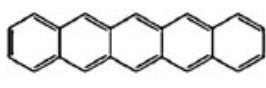

Pentacene<smiles>CC(CCCC(C)CCCC(C)CCC1C(C)CCCC1(C)C)CCCC(C)CCC(C)CCC1C(C)CCCC1C</smiles>

$\beta$-carotene

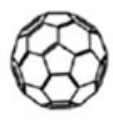

$\mathrm{C}_{60}$
Fig. 4 Natural materials or materials inspired by nature used for fabrication of environmentally sustainable OFETs. a Scheme of bottom-gate, top-contact OFET; b chemical structure of rosolic acid (aurin), used as smoothener; c substrates investigated; d natural dielectric materials in the nucleobase and sugar families; e semiconductor materials [20] 
Nucleobase (adenine, guanine, cytosine and thymine) and sugar (lactose, glucose) materials were chosen as the dielectric (Fig. 4d). Compounds like beta-carotene and indigo (natural p- and n-type semiconductor), indanthrene yellow $\mathrm{G}$ and indanthrene brilliant orange RF deriving from natural anthraquinone and perylene diimide, a cosmetic colour (Fig. 4e), were employed as the semiconductor. All these semiconductors are characterized by ease of synthesis, low price, low toxicity [70], biodegradability [71] and ability to be metabolized [72]. However, although these unusual materials appear to offer a promising route for fabrication of fully biodegradable organic electronics, extensive biocompatibility studies (including inflammation tests) should be performed to prove the feasibility of their use in implantable/ingestible devices. Nevertheless, it is noteworthy that the potential utilization of resorbable materials inspired by nature, apart from their interest in biosensing applications, could ultimately provide the basis for "sustainable green electronics", which is of great interest for low-cost, large-volume, disposable or throwaway electronic applications, such as in food packaging, plastic bags and disposable dishware.

\section{Microcantilevers}

The adsorption (physi- or chemi-, reversible or irreversible) or intercalation of an analyte onto the MCL changes its resonance frequency as well as its surface forces and results in a measurable MCL bending [73]. The detection of this bending can be divided in two different modes of operation: static and dynamic [10], as depicted in Fig. 5.

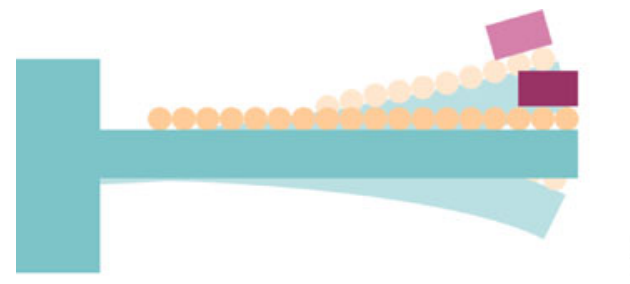

a

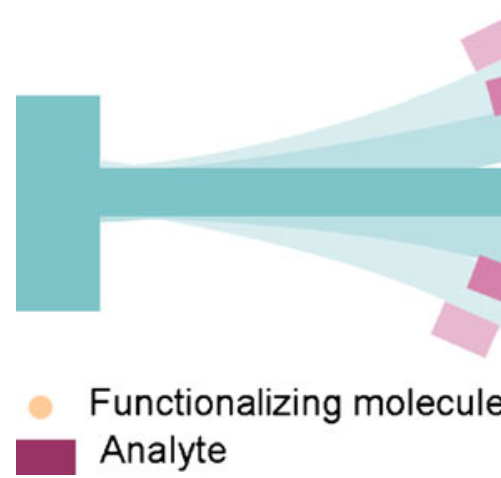

Fig. 5 Schematic of the two operation modes of MCLs: a static, b dynamic
Working in the static mode, the bending arises as a consequence of a surface stress change induced by any molecular reaction (i.e. physical adsorption or chemical bonding of the analytes) which takes places on only one of the cantilever surfaces, ad hoc modified in order to promote that reaction. In contrast to the static mode, in the dynamic mode the cantilever resonance frequency change depends on the total mass adsorbed on both sides.

By monitoring changes in the bending response of a cantilever, surface stress changes induced by either adsorption or molecular recognition can be accurately recorded. For the detection of cantilever deflection, optical [74], piezoresistive [75], piezoelectric [76] and capacitive [77] methods have been employed.

In order to enhance the sensitivity of the MCL sensor, the sensor surface can be modified through different surface modification methods, which can be both physical and chemical, as summarized by Prakash et al. [78]. Moreover, Chiari et al. [79] reported the surface modification methods of sensing elements by using polymers, in particular for biospecific recognition.

MCLs have been proposed for biological/biomedical, physical/chemical and environmental sensing as summarized in Fig. 6.

As far as the biomedical field is concerned, MCLs have been specifically designed for the screening of diseases, detection of point mutations, blood glucose monitoring and detection of chemical and biological warfare agents. In the last decade, this sensing technique has become very popular in biosensing since the first MCL to detect prostate-specific antigen (PSA), a prostate cancer marker, was proposed [80]. The authors coated the surface of the MCL with antibodies specific to PSA, over a range of concentrations from $0.2 \mathrm{ng} \mathrm{mL} \mathrm{g}^{-1}$ to $60 \mu \mathrm{g} \mathrm{mL}^{-1}$. When the PSA-coated MCL interacted with the blood sample of the patient, antigen-antibody complex was formed and the bending of the MCL occurred due to the adsorbed mass of the antigen molecules. Kim's group [81] used a novel electrical detection mode to measure PSA-antibody binding on the MCL surface, with a reported sensitivity of $10 \mathrm{ng} \mathrm{mL}^{-1}$. Subsequently, the same group fabricated the nanomechanical lead zirconate titanate (PZT) cantilever and carried out the detection of PSA by a novel electrical measurement using a composite layer of $\mathrm{Ta} / \mathrm{Pt} / \mathrm{PZT} / \mathrm{Pt} / \mathrm{SiO}_{2}$ on a $\mathrm{SiNx}$ supporting layer, reaching a detection sensitivity as low as $10 \mathrm{pg} \mathrm{mL}^{-1}$ [82].

As a matter of fact, most disease biomarkers are not sufficiently selective and this implies that the detection of a single biomarker cannot be used for the positive identification of a disease, i.e. multiple tests are required. In the successive studies, MCLs for biomedical applications have been used in an array format for the sensitive and simultaneous measurement of multiple unlabelled analytes. These 


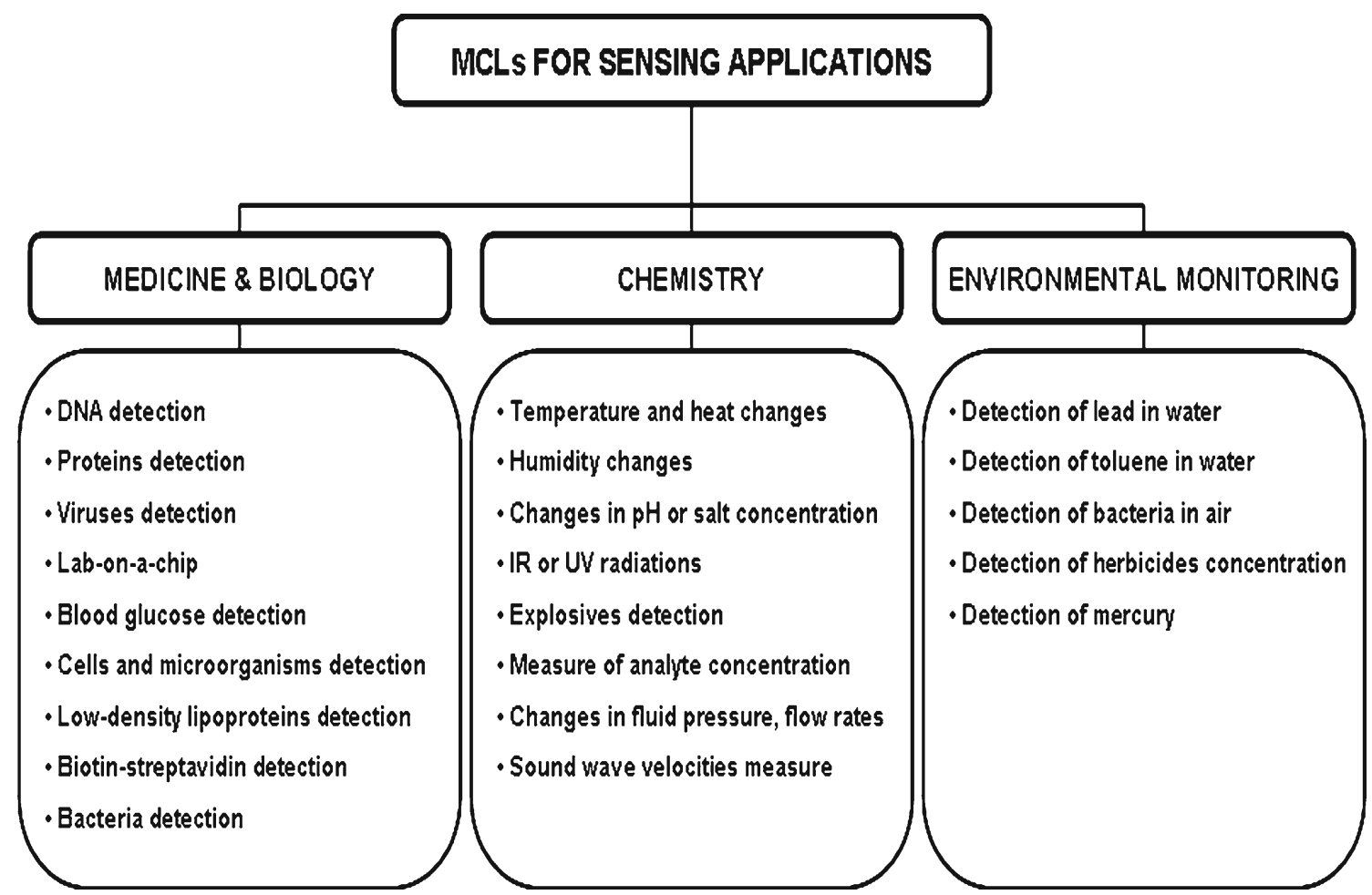

Fig. 6 Sensing applications of MCLs

MCL array sensors have attracted considerable attention over the last decade. The array approach was used, for example, for toxins or pathogens detection [83], in investigations on DNA hybridization [84] and as a sensing system for cancer diagnosis [85].

The new trend in MCL applications in the in vivo sensing, diseases detection, drug monitoring or delivery is to improve the biological specificity in recognition. This is typically achieved by properly modifying the MCL surface either by immobilizing selective receptors or probe molecules, or by stimuli-responsive polymer coatingssuch as films or brushes-or nanoparticles/nanotubes, able to entrap specific analytes as a consequence of a specific stimulus.

These modified materials are considered outstanding candidates for assembling "smart" or "intelligent" active structures. Different classes of polymers or inorganic materials could be classified as smart materials. Among these, hydrogels are able to drastically change their volume due to water exposure (see Fig. 7a) [86]. Moreover, amino- or carboxylterminated self-assembled monolayers (SAMs) can be employed to covalently bond proteins, using cross linkers such as glutaraldehyde or 1-ethyl-3-(3-dimethylaminopropyl)carbodiimide (EDC) with $\mathrm{N}$-hydroxysuccinimide (NHS) (see Fig. 7b) [86]. Finally, amphiphilic block copolymers are able to orientate their blocks in response to the
Fig. 7 Response of MCLs when using a a polymer, b SAMs sensing layers [86]
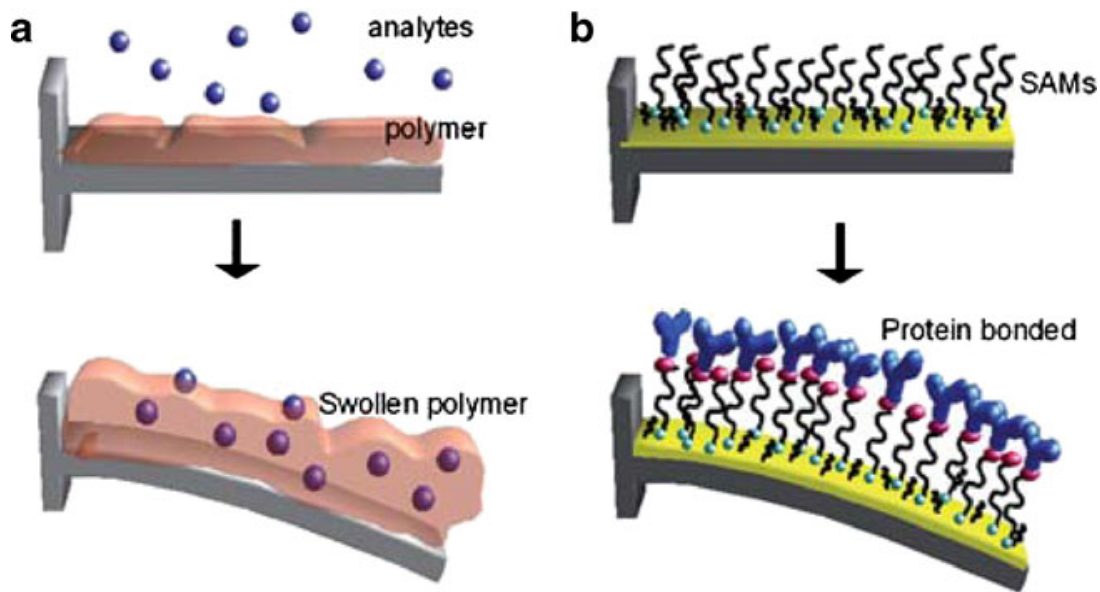
hydrophilic or hydrophobic nature of the medium in which they are immersed.

Different thin films of homopolymers and copolymers [87-90], amphiphilic block copolymers [91], polymer brushes [92], nanotubes [93] and nanoparticles [94] have been proposed as potential smart materials both for novel biomaterials development and for biosensing applications.

Peppas and collaborators [95] reported a modified photolithography method to pattern $\mathrm{pH}$-sensitive hydrogels onto silicon MCLs for the development of $\mathrm{pH}$ microsensors; as a further step, different stimuli-responsive hydrogels were put on different cantilevers all within one chip, thus creating an implantable microdevice able to monitor a wide variety of biomolecules [96, 97].

Yan et al. [98] reported a new approach of glucose measurement by using a multilayer modified MCL. Glucose oxidase (GOx)/polyethyleneimine (PEI) multilayer modified MCL underwent bending when it was exposed to glucose solutions, with magnitudes of bending proportional to the concentrations of glucose. Moreover, $\mathrm{pH}$-responsive polymer brushes have been employed as glucose MCLbased sensors [99].

As far as the genomics research is concerned, efforts have been made to detect point mutations for the early diagnosis of several diseases such as thalassemia, Tay-Sachs, and Alzheimer's disease. MCLs could represent an effective and reliable way of detecting such single-base pair mismatches, due to the specific biomolecular recognition interactions between the probe DNA sequence and the target DNA sequence. If the hybridization with the fully complementary target DNA sequence causes the net positive deflection of the cantilever, a minor degree of deflection occurs as the number of base pair mismatches increases [74]. More recently, PZT-embedded MCLs have been fabricated in order to detect how secondary structures in oligonucleotide monolayer change the surface properties of a dynamic mode MCL [100].

Koev et al. [101] electrodeposited chitosan films onto the cantilever and biofunctionalized the film with an oligonucleotide probe, in order to detect target DNA hybridization by cantilever bending. Binding of either target DNA to immobilized probe DNA or of oxidized dopamine to chitosan amine groups causes bending of the cantilever beam which is measured using an optical probe (see Fig. 8).

Moreover, the chitosan-coated cantilever was biased to electrochemically oxidize and thus selectively detect the neurotransmitter dopamine. The mechanism of interaction of dopamine with chitosan nanoparticles has been recently studied by quartz crystal microbalance with dissipation monitoring (QCM-D) technology [102].

As a result of their excellent performance MCLs have recently emerged for the detection not only of small molecules, but also of nucleic acids, disease marker proteins [103-105], cells [106] and different bacteria or viruses $[107,108]$.

In particular, MCLs-based biosensors seem to be capable of rapid and ultrasensitive detection of bacteria, thus promising significant enhancements of microbiological research and diagnostics. For example, Ilic et al. reported the detection of sixteen specifically bound $E$. coli cells, using an MCL array covered with specific antibodies [109].

Moreover, PZT-stainless steel cantilevers were used by Yi et al. as real-time in-water cell detectors using yeast cells

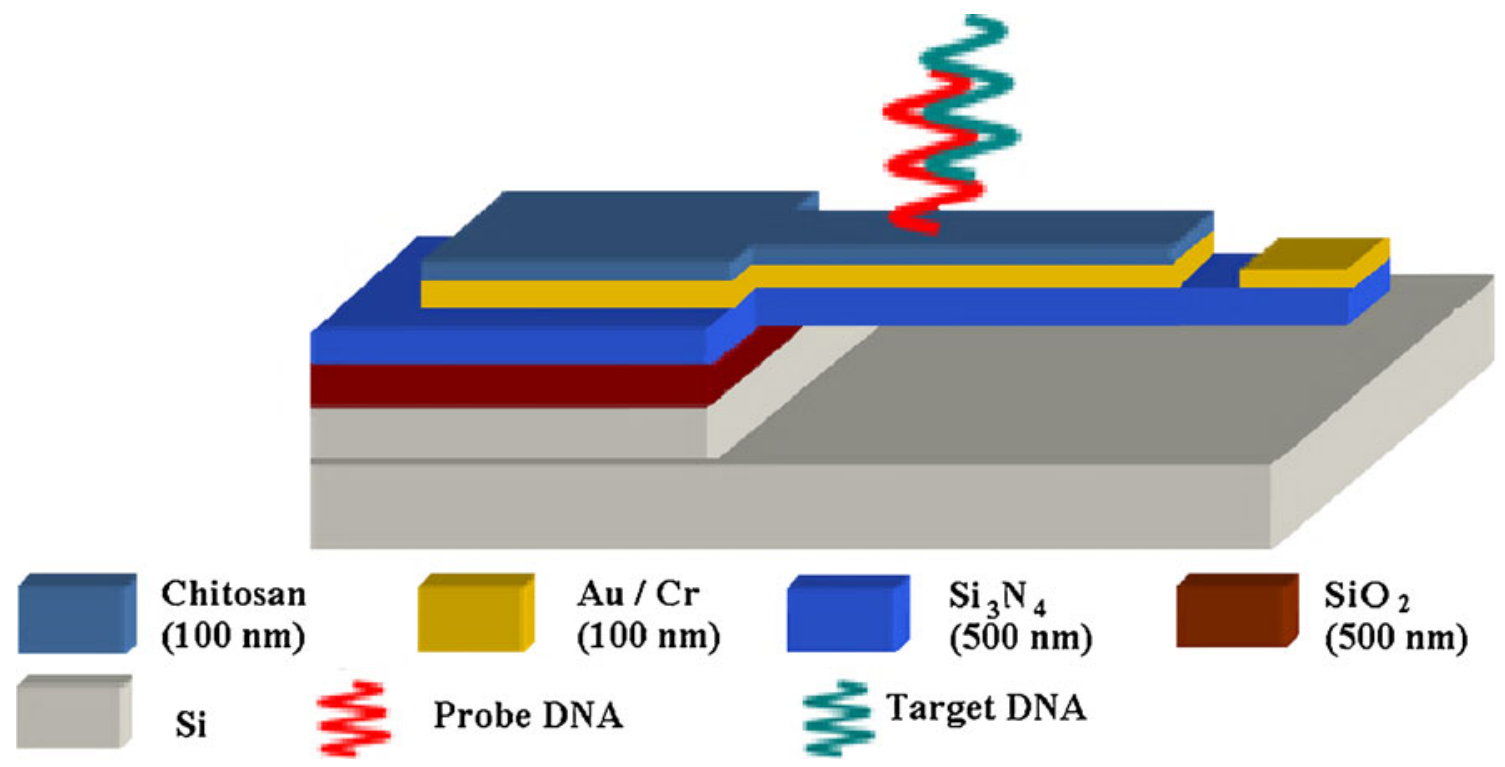

Fig. 8 Cross-sectional scheme of an MCL surface modified with chitosan for detection of DNA hybridization 
as a model system [110]. In particular, the yeast cells were immobilized on the cantilever tip as a result of their interaction with poly-L-lysine that precoated the tip.

Park et al. used "living cantilever arrays" for the mass characterization of single adherent cells, working under physiological conditions, by dividing the vibration spectrum from the cantilever by that of the non-moving substrate: the adherent cell was captured and cultured directly on the silicon cantilever [111].

Another study revealed the ability of short peptide ligands to efficiently capture Bacillus subtilis spores in liquids, immobilizing these ligands on an eight-cantilever array chip [112]. Another example of cell detection was reported by Sungkanak and co-workers, who designed an MCL-based Vibrio cholerae O1 sensor by immobilizing a monoclonal antibody onto the gold-coated MCL tip by using a SAM of mercaptopropionic acid. EDC was used to activate the carboxylic groups of the acid in order to form the peptide bond with the amine groups of the antibody [113]. The detection limit of this sensor was about $1 \times$ $10^{3} \mathrm{CFU} \mathrm{mL}^{-1}$.

MCL technology was also employed to detect severe acute respiratory syndrome associated coronavirus (SARS$\mathrm{CoV}$ ), with detection limits of $0.1 \mu \mathrm{g} \mathrm{mL}^{-1}$ [114].

A very interesting approach in detecting cancer cells could be measuring the cell stiffness: the cell stiffness here is itself the biomarker thus making it possible to differentiate cancer cells from normal healthy cells. Darling at al. [115] extensively argued about the capability of AFM to quantify the biophysical properties of single cells. In this respect, a possible future development of the MCL technology could be the ability to measure cell mechanical properties and to relate these features to cell differentiation, transformation and malignancy.

\section{Microcantilevers vs. organic transistors: comparison and future perspectives}

Recent advances and trends in the development of OFETs, OECTs and MCLs as biosensing devices have been reviewed. The increasing demand for sensitive, selective and miniaturized tools for the investigation of living systems and for the early diagnosis of disease are the main drivers for the development of advanced systems able to address complex biomedical issues and at the same time offering low-cost, rapid and reliable multiplex detection. Label-free processes directly assessing biorecognition events are a challenging alternative to the currently available diagnostic biological assays (ELISA, polymerase chain reactions) routinely used in clinical analysis [116]. Although these methods are high-throughput and reliable, they provide results only after several incubations, washing and separation steps. In addition, the transduction of the biorecognition event requires the "labelling" of the bioanalyte, thus adding further sample handling before the analysis can be performed. Therefore, smaller, faster and cheaper devices are highly desired for replacing these time-consuming laboratory analyses also allowing for analytical results available directly at the doctor's office or even the patient's house. In this respect, labelfree biosensors seem to be very promising. Although optical [117, 118], electrochemical and electronic [119, 120] label-free biosensors were reported extensively, most of these devices show several disadvantages especially in terms of cost fabrication, miniaturization, regeneration and reproducibility.

Both MCL and organic transistor technologies are able to overcome these drawbacks and improve the performance of devices currently on the market. These devices together with label-free detection capabilities hold advantages such as the possibility to be integrated into an electronic circuit and cost-effective mass production using large-area electronic technologies [121-123]. In this respect it must be underlined that MCLs can be fabricated through standard integrated circuit production procedures based on silicon technology, a much more mature approach than organic electronics technology.

Organic electronics-based biosensors combine the specificity of a defined bioprobe with the label-free and high sensitivity of an organic transistor. These devices, compared to MCLs, offer the unique advantages of a multi-parametric response and a gate enhanced sensitivity [30]. In addition to this, the ability to directly transduce the biological event into an electrical signal allows a direct treatment of the results thus avoiding expensive equipment used in optical systems. Besides, they show quite a good selectivity, by properly functionalizing the semiconductor backbone [30, 124], and can also be fabricated in an array configuration, often required for disease diagnosis and in general for the study of complex biological systems, on flexible plastic or paper substrates by low cost printing compatible procedures [125]. The flexibility holds additional advantages in the case of direct contact with soft tissues. One critical issue of organic transistors is their complex architecture: materials with different features such as an organic semiconductive layer and an insulating (dielectric) layer must be selected/ synthesised and assembled in a proper configuration in order to fabricate working devices. On the other hand MCL architecture is definitively simpler.

MCL-based biosensors show several advantages over the conventional sensing systems, in terms of high sensitivity (based on the ability to detect cantilever deflection with subnanometre precision), label-free, quick response, low analyte requirement (on the order of few microliters), array capability and miniaturization, which make them particularly suitable for in vivo physiological monitoring. 
The main disadvantage of the MCLs is the lack of specificity of their transduction mechanism; however, that can often be overcome by modifying the sensing surface in order to promote selective biochemical reactions (i.e. receptor-ligand, antibody-antigen or enzyme-substrate reactions etc.).

In conclusion, both organic transistors and MCLs possess the requisites necessary for devices of interest in life science applications and possess such a high sensitivity as to even be able to detect single cells; very recently, an interesting combination between an OFET and a polymer cantilever platform was proposed. This sensor was named "Organic CantiFET" [126]. Such an integrated system could represent the next generation of biosensors, combining all the advantages of two different but similarly well-performing devices.

The present review has been mainly focused on devices based on organic materials as the active layer. Apart from their intrinsic mechanical, electrical and processing properties they ensure an intimate contact with biological tissues and can be easily engineered owing to their synthetic tailorability. In order to match the biocompatibility requirement research efforts are currently underway both in the manipulation and modification of well-established materials and in the search for new materials. In particular, recent results obtained in the fabrication of OFETs by using "exotic" materials inspired by nature have been reviewed. As a future perspective, once the materials' biocompatibility has been proved, this approach could pave the way to the development of a completely new class of implantable/ingestible devices.

\section{References}

1. Svennersten K, Larsson KC, Berggren M, Richter-Dahlfors A (2011) Organic bioelectronics in nanomedicine. Biochim Biophys Acta 1810:276-285

2. Berggren M, Richter-Dahlfors A (2007) Organic bioelectronics. Adv Mater 19:3201-3213

3. Owens RM, Malliaras GG (2010) Organic electronics at the interface with biology. MRS Bull 35:449-456

4. Asplund M, Nyberg T, Inganas O (2010) Electroactive polymers for neural interfaces. Polym Chem 1:1374-1391

5. Yang SY, Kim BN, Zakhidov AA, Taylor PG, Lee JK, Ober CK, Lindau M, Malliaras GG (2011) Detection of transmitter release from single living cells using conducting polymer microelectrodes. Adv Mater 23:H184-H188

6. Green RA, Baeck S, Poole-Warren LA, Martens PJ (2010) Conducting polymer-hydrogels for medical electrode applications. Adv Mater 11:014107-014119

7. Jones IL, Livi P, Lewandowska MK, Fiscella M, Roscic B, Hierlemann A (2011) The potential of microelectrode arrays and microelectronics for biomedical research and diagnostics. Anal Bioanal Chem 399:2313-2329

8. Torsi L, Tanese MC, Crone B, Wang L, Dodabalapur A (2007) Organic transistor chemical sensors. In: Bao Z, Locklin J (ed) Organic field-effect transistors, CRC, Boca Raton
9. Sokolov AN, Roberts ME, Bao Z (2009) Fabrication of low-cost electronic biosensors. Mater Today 12:12-20

10. Datskos PG, Lavrik NV, Sepaniak MJ (2004) Chemical and biological sensors based on microcantilevers. In: Yurish SY, Gomes MTSR (ed) Smart sensors and MEMS, vol 181. Kluwer, Dordrecht, pp 331-379

11. Bashir R (2004) BioMEMS: state-of-the-art in detection, opportunities and prospects. Adv Drug Deliver Rev 56:1565-1586

12. Crone B, Dodabalapur A, Lin YY, Filas RW, Bao Z, La Duca A, Sarpeshkar R, Katz HE, Li W (2000) Large scale complementary integrated circuits based on organic transistors. Nature 403:521523

13. Karrasch S, Hegerl R, Hoh JH, Baumeister W, Engel A (1994) Atomic force microscopy produces faithful high-resolution images of protein surfaces in an aqueous environment. Proc Natl Acad Sci USA 91:836-838

14. Muller DJ, Schabert FA, Buldt G, Engel A (1995) Imaging purple membranes in aqueous solutions at sub-nanometer resolution by atomic force microscopy. Biophys J 68:1681-1686

15. Gimzewski JK, Gerber C, Meyer E, Schlittler RR (1994) Observation of a chemical reaction using a micromechanical sensor. Chem Phys Lett 217:589-594

16. Kelley TW, Baude PF, Gerlach C, Ender DE, Muyres D, Haase MA, Vogel DE, Theiss SD (2004) Recent progress in organic electronics: materials, devices and processes. Chem Mater 16:4413-4422

17. Simon DT, Kurup S, Larsson KC, Hori R, Tybrandt K, Goiny M, Jager EWH, Berggren M, Canlon B, Richter-Dahlfors A (2009) Organic electronics for precise delivery of neurotransmitters to modulate mammalian sensory function. Nat Mater 8:742-746

18. Guimard NK, Gomez N, Schmidt CE (2007) Conducting polymers in biomedical engineering. Prog Polym Sci 32:876-921

19. Irimia-Vladu M, Sariciftci NS, Bauer S (2011) Exotic materials for bio-organic electronics. J Mater Chem 21:1350-1361

20. Irimia-Vladu M, Troshin PA, Reisinger M, Schwabegger G, Ullah M, Schwödiauer R, Mumyatov A, Bodea M, Fergus JW, Razumov VF, Sitter H, Bauer S, Sariciftci NS (2010) Environmentally sustainable organic field effect transistors. Org Electron 11:1974-1990

21. Irimia-Vladu M, Troshin PA, Reisinger M, Shmygleva L, Kanbur Y, Schwabegger G, Bodea M, Schwödiauer R, Mumyatov A, Fergus JW, Razumov VF, Sitter H, Sariciftci NS, Bauer S (2010) Biocompatible and biodegradable materials for organic field-effect transistors. Adv Funct Mater 20:4069-4076

22. Bettinger CJ, Bao Z (2010) Organic thin-film transistors fabricated on resorbable biomaterial substrates. Adv Mater 22:651-655

23. Horowitz G (1998) Organic field effect transistors. Adv Mater 10:365-377

24. Bernards DA, Malliaras GG (2007) Steady-state and transient behavior of organic electrochemical transistors. Adv Funct Mater $17: 3538-3544$

25. Duarte D, Sharm D, Cobb B, Dodabalapur A (2011) Charge transport and trapping in organic field effect transistors exposed to polar analytes. Appl Phys Lett 98:133302/1-133302/3

26. Torsi L, Palazzo G, Mallardi A, Angione MD, Cotrone S (2010) In: Samori P, Cacialli F (eds) Functional supramolecular architectures for organic electronics and nanotechnology. Wiley-VCH, Weinheim

27. Mabeck JT, Malliaras GG (2006) Chemical and biological sensors based on organic thin-film transistors. Anal Bioanal Chem 384:343-353

28. Torsi L (2006) Organic thin-film transistors as analytical and bioanalytical sensors. Anal Bioanal Chem 384:309-309

29. Kim JM, Jha SK, Chand R, Lee DH, Kim YS (2011) DNA hybridization sensor based on pentacene thin film transistor. Biosens Bioelectron 26:2264-2269 
30. Torsi L, Farinola GM, Marinelli F, Tanese MC, Omar OH, Valli L, Babudri F, Palmisano F, Zambonin PG, Naso F (2008) A sensitivity-enhanced field-effect chiral sensor. Nat Mater 7:412419

31. Maddalena F, Kuiper MJ, Poolman B, Brouwer F, Hummelen JC, de Leeuw DM, De Boer B, Blom PWM (2010) Organic fieldeffect transistor-based biosensors functionalized with protein receptors. J Appl Phys 108:124501/1-124501/4

32. Angione MD, Pilolli R, Cotrone S, Magliulo M, Mallardi A, Palazzo G, Sabbatini L, Fine D, Dodabalapur A, Cioffi N, Torsi L (2011) Carbon based materials for electronic bio-sensing. Mater Today 14:424-433

33. Someya T, Dodabalapur A, Gelperin A, Katz HE, Bao Z (2002) Integration and response of organic electronics with aqueous microfluidics. Langmuir 18:5299-5302

34. Feili D, Schuettler M, Doerge T, Kammer S, Stieglitz T (2005) Encapsulation of organic field effect transistors for flexible biomedical microimplants. Sensor Actuat A Phys 120:101-109

35. Khan HU, Roberts ME, Johnson O, Förch R, Knoll W, Bao Z (2010) In situ, label-free DNA detection using organic transistor sensors. Adv Mater 22:4452-4456

36. Roberts ME, Mannsfeld SCB, Queraltó N, Reese C, Locklin J, Knoll W, Bao Z (2008) Water-stable organic transistors and their application in chemical and biological sensors. Proc Natl Acad Sci USA 105:12134-12139

37. Zhu ZT, Mason JT, Dieckermann R, Malliaras GG (2002) Humidity sensors based on pentacene thin-film transistors. Appl Phys Lett 81:4643-4645

38. Chaabane RB, Ltaief A, Kaabi L, Ouada HB, Jaffrezic-Renault $\mathrm{N}$, Davenas J (2006) Influence of ambient atmosphere on the electrical properties of organic thin film transistors. Mater Sci Eng C 26:514-518

39. Flemming RG, Murphy CJ, Nealey PF (1999) Effects of synthetic micro- and nano-structured surfaces on cell behavior. Biomaterials 20:573-588

40. Kikuchi A, Okano T (2005) Nanostructured designs of biomedical materials: applications of cell sheet engineering to functional regenerative tissues and organs. J Control Release 101:69-84

41. Ma J, Cui FZ, Xu QY (2007) Atomic force and confocal microscopy for the study of cortical cells cultured on silicon wafers. J Mater Sci Mater Med 18:851-856

42. Ainslie KM, Bachelder EM, Pishko MV (2007) Cell adhesion on nanofibrous polytetrafluoroethylene (nPTFE). Langmuir 23:747754

43. Choi CH, Hagvall SH, Kim CJ (2007) Cell interaction with threedimensional sharp-tip nanotopography. Biomaterials 28:1672-1679

44. Price R, Ellison K, Webster T (2004) Nanometer surface roughness increases select osteoblast adhesion on carbon nanofiber compacts. J Biomed Mater Res 70:129-138

45. Eisenbarth E, Velten D, Breme J (2006) Nanostructured niobium oxide coatings influence osteoblast adhesion. J Biomed Mater Res A 79:166-175

46. Kunzler TP, Drobek T, Spencer ND (2007) Systematic study of osteoblast and fibroblast response to roughness by means of surface morphology gradients. Biomaterials 28:2175-2182

47. Wong JY, Langer R, Ingber DE (1994) Electrically conducting polymers can noninvasively control the shape and growth of mammalian cells. Proc Natl Acad Sci USA 91:3201-3204

48. Bystrenova E, Jelitai M, Tonazzini I, Lazar AN, Huth M, Stoliar P, Dionigi C, Cacace MG, Nickel B, Madarasz E, Biscarini F (2008) Neural networks grown on organic semiconductors. Adv Funct Mater 18:1751-1756

49. Scarpa G, Idzko AL, Goetz SM, Thalhammer S (2010) Biocompatibility studies of functionalized regioregular poly (3-hexylthiophene) layers for sensing applications. Macromol Biosci 10:378-383
50. Goetz SM, Erlen CM, Grothe H, Wolf B, Lugli P, Scarpa G (2009) Organic field effect transistors for biosensing applications. Org Elect 10:573-580

51. Scarpa G, Idzko AL, Yadav A, Thalhammer S (2010) Organic ISFET based on poly (3-hexylthiophene). Sensors 10:2262-2273

52. Kittlesen GP, White HS, Wrighton MS (1984) Chemical derivatization of microelectrode arrays by oxidation of pyrrole and $\mathrm{N}$ methylpyrrole: fabrication of molecule-based electronic devices. J Am Chem Soc 106:7389-7396

53. Nilsson D, Kugler T, Svensson PO, Berggren M (2002) An allorganic sensor-transistor based on a novel electrochemical transducer concept printed electrochemical sensors on paper. Sensor Actuat B Chem 86:193-197

54. Bernards DA, Malliaras GG, Toombes GES, Grunerb SO (2006) Gating of an organic transistor through a bilayer lipid membrane with ion channels. Appl Phys Lett 89:053505/1-053505/3

55. Nyberg T, Shimada A, Torimitsu K (2007) Ion conducting polymer microelectrodes for interfacing with neural networks. J Neurosci Methods 160:16-25

56. Gumus A, Califano JP, Wan AMD, Huynh J, Reinhart-King CA, Malliaras GG (2010) Control of cell migration using a conducting polymer device. Soft Matter 6:5138-5142

57. Wan AMD, Brooks DJ, Gumus A, Fischbach C, Malliaras GG (2009) Electrical control of cell density gradients on a conducting polymer surface. Chem Commun 35:5278-5280

58. Isaksson J, Kjäll P, Nilsson D, Robinson ND, Berggren M, Richter-Dahlfors A (2007) Electronic control of $\mathrm{Ca}^{2+}$ signalling in neuronal cells using an organic electronic ion pump. Nat Mater 6:673-679

59. Bolin MH, Svennersten K, Nilsson D, Sawatdee A, Jager EWH, Richter-Dahlfors A, Berggren M (2009) Active control of epithelial cell-density gradients grown along the channel of an organic electrochemical transistor. Adv Mater 21:4379-4382

60. Lin P, Yan F, Yu J, Chan HLW, Yang M (2010) The application of organic electrochemical transistors in cell-based biosensors. Adv Mater 22:3655-3660

61. Crowe DL, Kim R, Chandraratna RAS (2003) Retinoic acid differentially regulates cancer cell proliferation via dose-dependent modulation of the mitogen-activated protein kinase pathway. Mol Cancer Res 1:532-540

62. McGinness J, Corry P, Proctor P (1974) Amorphous semiconductor switching in melanins. Science 183:853-855

63. Wiltz A, Pritchard EM, Li T, Lan JO, Kaplan DL, Boison D (2008) Silk polymer-based adenosine release: therapeutic potential for epilepsy. Biomaterials 29:3609-3616

64. Lee JS, Chae GS, Kim MS, Cho SH, Lee HB, Khang G (2004) Degradation behaviour in vitro for poly(D,L-lactide-co-glycolide) as drug carrier. Biomed Mater Eng 14:185-192

65. Ferreira L, Gerecht S, Fuller J, Shieh HF, Vunjak-Novakovic G, Langer R (2007) Bioactive hydrogel scaffolds for controllable vascular differentiation of human embryonic stem cells. Biomaterials 28:2706-2717

66. Bosetti M, Massè A, Tobin E, Cannas M (2002) Silver coated materials for external fixation devices: in vitro biocompatibility and genotoxicity. Biomaterials 23:887-892

67. Edelman ER, Seifert P, Groothuis A, Morss A, Bornstein D, Rogers C (2001) Gold-coated NIR stents in porcine coronary arteries. Circulation 103:429-434

68. Foresti R, Hoque M, Monti D, Green CJ, Motterlini R (2005) Differential activation of heme oxygenase-1 by chalcones and rosolic acid in endothelial cells. J Pharmacol Exp Ther 312:686-693

69. Fang H, Tong W, Branham WS, Moland CL, Dial SL, Hong H, Xie Q, Perkins R, Owens W, Sheehan DM (2003) Study of 202 natural, synthetic, and environmental chemicals for binding to the androgen receptor. Chem Res Toxicol 16:1338-1358 
70. Environment Canada (2009) Substance profile for the challenge benzo $[h]$ benz $[5,6]$ acridino[2,1,9,8-klmna $]$ acridine-8, 16-dione (pigment yellow 24), Chemical Abstracts Service Registry Number 475-71-8. Environment Canada, March 2009

71. Liu J, Luo H (2007) Degradation of anthraquinone dyes by ozone. Trans Nonferrous Met Soc China 17:880-886

72. Olaganathan R, Patterson J (2009) Decolorization of anthraquinone vat blue 4 by the free cells of an autochthonous bacterium, Bacillus subtilis. Water Sci Technol 16:3225-3232

73. Goeders KM, Colton JS, Bottomley LA (2008) Microcantilevers: sensing chemical interactions via mechanical motion. Chem Rev 108:522-542

74. Hansen KM, Ji HF, Wu G, Datar R, Cote R, Majumdar A, Thundat T (2001) Cantilever-based optical deflection assay for discrimination of DNA single-nucleotide mismatches. Anal Chem 73:1567-1571

75. Pinnaduwage LA, Gehl A, Hedden DL, Muralidharan G, Thundat T, Lareau RT, Sulchek T, Manning L, Rogers B, Jones M, Adams JD (2003) Explosives: a microsensor for trinitrotoluene vapour. Nature 425:474-474

76. Yamada H, Itoh $\mathrm{H}$, Watanabe S, Kobayashi K, Matsushige $\mathrm{K}$ (1999) Scanning Near-field optical microscopy using piezoelectric cantilevers. Surf Interface Anal 27:503-506

77. Thundat T, Oden PI, Warmack RJ (1997) Microcantilever sensors. Microscale Therm Eng 1:185-199

78. Prakash S, Karacor MB, Banerjee S (2009) Surface modification in microsystems and nanosystems. Surf Sci Rep 64:233-254

79. Chiari M, Cretich M, Damin F, Di Carlo G, Oldani C (2008) Advanced polymers for molecular recognition and sensing at the interface. J Chromatogr B 866:89-103

80. Wu GH, Datar RH, Hansen KM, Thundat T, Cote RJ, Majumdar A (2001) Bioassays of prostate-specific antigen (PSA) using microcantilevers. Nat Biotechnol 19:856-860

81. Lee JH, Hwang KS, Park J, Yoon KH, Yoon DS, Kim TS (2005) Immunoassay of prostate-specific antigen (PSA) using resonant frequency shift of piezoelectric nanomechanical microcantilever. Biosens Bioelectron 20:2157-2162

82. Wee KW, Kang GY, Park J, Kang JY, Yoon DS, Park JH, Kim TS (2005) Novel electrical detection of label-free disease marker proteins using piezoresistive self-sensing micro-cantilevers. Biosens Bioelectron 20:1932-1938

83. Shih WY, Campbell G, Yi JW, Luo H, Mutharasan R, Shi WH (2004) In: Karn B, Masciangioli T, Zhang WX, Colvin V, Alivasatos $\mathrm{P}$ (eds) Ultrasensitive pathogen quantification in drinking water using highly piezoelectric microcantilevers. Nanotechnology and the environment applications and implications. American Chemical Society, Washington

84. Mukhopadhyay R, Lorentzen M, Kjems J, Besenbacher F (2005) Nanomechanical sensing of DNA sequences using piezoresistive cantilevers. Langmuir 21:8400-8408

85. Datar R, Kim S, Jeon S, Hesketh P, Manalis S, Boisen A, Thundat T (2009) Cantilever sensors: nanomechanical tools for diagnostics. Mrs Bull 34:449-454

86. Alvarez M, Lechuga LM (2010) Microcantilever-based platforms as biosensing tools. Analyst 135:827-836

87. Gonska J, Schelling C, Urban G (2009) Application of hydrogelcoated microcantilevers as sensing elements for $\mathrm{pH}$. J Micromech Microeng 19:127002/1-127002/8

88. De Giglio E, Cometa S, Satriano C, Sabbatini L, Zambonin PG (2009) Electrosynthesis of hydrogel films on metal substrates for the development of coatings with tunable drug delivery performances. J Biomed Mater Res A 88(4):1048-1057

89. De Giglio E, Cafagna D, Ricci MA, Sabbatini L, Cometa S, Ferretti C, Mattioli-Belmonte M (2010) Biocompatibility of poly(acrylic acid) thin coatings electro-synthesized onto TiAlVbased implants. J Bioact Compat Pol 25:374-391
90. De Giglio E, Cafagna D, Giangregorio MM, Domingos M, Mattioli-Belmonte M, Cometa S (2011) PHEMA-based thin hydrogel films for biomedical applications. J Bioact Compat Pol 26:420-434

91. Cometa S, Bartolozzi I, Corti A, Chiellini F, De Giglio E, Chiellini E (2010) Hydrolytic and microbial degradation of multiblock polyurethanes based on poly( $\varepsilon$-caprolactone)/poly(ethylene glycol) segments. Polym Degrad Stabil 95:2013-2021

92. Abu-Lail NI, Kaholek M, LaMattina B, Clark RL, Zauscher S (2006) Microcantilevers with end-grafted stimulus-responsive polymer brushes for actuation and sensing. Sens Actuators B 114:371-378

93. Bi S, Zhou H, Zhang S (2009) Multilayers enzyme-coated carbon nanotubes as biolabel for ultrasensitive chemiluminescence immunoassay of cancer biomarker. Biosens Bioelectron 24:29612966

94. de la Escosura-Muñiz A, Parolo C, Merkoçi A (2010) Immunosensing using nanoparticles. Mater Today 13:24-30

95. Bashir HJ, Elibol O, Gupta A, Peppas N (2002) Micromechanical cantilever as an ultrasensitive $\mathrm{pH}$ microsensor. Appl Phys Lett 81:3091-3093

96. Hilt JZ, Gupta AK, Bashir R, Peppas NA (2003) Ultrasensitive biomems sensors based on microcantilevers patterned with environmentally responsive hydrogels. Biomed Microdevices 5:177-184

97. Peppas NA (2006) Intelligent biomaterials as pharmaceutical carriers in microfabricated and nanoscale devices. Mater Res Soc Bull 31:888-893

98. Yan X, Ji HF, Lvov Y (2004) Modification of microcantilevers using layer-by-layer nanoassembly film for glucose measurement. Chem Phys Lett 396:34-37

99. Chen T, Chang DP, Liu T, Desikan R, Datar R, Thundat T, Berger $\mathrm{R}$, Zauscher S (2010) Glucose-responsive polymer brushes for microcantilever sensing. J Mater Chem 20:3391-3395

100. Zheng S, Choi JH, Lee SM, Hwang KS, Kim SK, Kim TS (2011) Analysis of DNA hybridization regarding the conformation of molecular layer with piezoelectric microcantilevers. Lab Chip 11:63-69

101. Koev ST, Powers MA, Yi H, Wu LQ, Bentley WE, Rubloff GW, Payne GF, Ghodssi R (2007) Mechano-transduction of DNA hybridization and dopamine oxidation through electrodeposited chitosan network. Lab Chip 7:103-111

102. De Giglio E, Trapani A, Cafagna D, Sabbatini L, Cometa S (2011) Dopamine-loaded chitosan nanoparticles: formulation and analytical characterization. Anal Bioanal Chem 400:19972002

103. Liu Y, Li X, Zhang Z, Zuo G, Cheng Z, Yu H (2009) Nanogram per milliliter-level immunologic detection of alpha-fetoprotein with integrated rotating-resonance microcantilevers for early-stage diagnosis of heptocellular carcinoma. Biomed Microdevices 11:183191

104. von Muhlen MG, Brault ND, ScottM K, Jiang S, Manalis SR (2010) Label-free biomarker sensing in undiluted serum with suspended microchannel resonators. Anal Chem 82:1905-1910

105. Ricciardi C, Fiorilli S, Bianco S, Canavese G, Castagna R, Ivan F, Digregorio G, Marasso SL, Napione L, Bussolino F (2010) Development of microcantilever-based biosensor array to detect angiopoietin-1, a marker of tumor angiogenesis. Biosens Bioelectron 25:1193-1198

106. Musick KM, Coffey AC, Irazoqui PP (2010) Sensor to detect endothelialization on an active coronary stent. Biomed Eng Online 9:67-73

107. Cha BH, Lee SM, Park JC, Hwang KS, Kim SK, Lee YS, Ju BK, Kim TS (2009) Detection of hepatitis B virus (HBV) DNA at femtomolar concentrations using a silica nanoparticle-enhanced microcantilever sensor. Biosens Bioelectron 25:130-135 
108. Caygill RL, Blair GE, Millner PA (2010) A review on viral biosensors to detect human pathogens. Anal Chim Acta 681:8-15

109. Ilic B, Czaplewski D, Craighead HG, Neuzil P, Campagnolo C, Batt C (2000) Mechanical resonant immunospecific biological detector. Appl Phys Lett 77:450-452

110. Yi JW, Shih WY, Mutharasan R, Shih WH (2003) In situ cell detection using piezoelectric lead zirconate titanate-stainless steel cantilevers. J Appl Phys 93:619/1-619/7

111. Park K, Jang J, Irimia D, Sturgis J, Lee J, Robinson JP, Toner M, Bashir R (2008) 'Living cantilever arrays' for characterization of mass of single live cells in fluids. Lab Chip 8:1034-1041

112. Babita D, Henne WA, Doorneweerd DD, Reifenberger RG, Low PS (2006) Detection of Bacillus subtilis spores using peptidefunctionalized cantilever array. J Am Chem Soc 128:3716-3721

113. Sungkanak U, Sappat A, Wisitsoraat A, Promptmas C, Tuantranont A (2010) Ultrasensitive detection of Vibrio cholerae O1 using microcantilever-based biosensor with dynamic force microscopy. Biosens Bioelectron 26:784-789

114. Velanki S, Ji HF (2006) Detection of feline coronavirus using microcantilever sensors. Meas Sci Technol 17:2964-2968

115. Darling EM, Zauscher S, Block JA, Guilak F (2007) A thin-layer model for viscoelastic, stress-relaxation testing of cells using atomic force microscopy: do cell properties reflect metastatic potential? Biophys J 92:1784-1791

116. Bailey AM, Mitchell DJ, Manjunath KL, Nolasco G, Niblett CL (2002) Identification to the species level of the plant pathogens Phytophthora and Pythium by using unique sequences of the ITS1 region of ribosomal DNA as capture probes for PCR ELISA. FEMS Microbiol Lett 207:153-158

117. Neuzil P, Reboud J (2008) Palm-sized biodetection system based on localized surface plasmon resonance. Anal Chem 80:6100-6103
118. Nazirizadeh Y, Bog U, Sekula S, Mappes T, Lemmer U, Gerken M (2010) Low-cost label-free biosensors using photonic crystals embedded between crossed polarizers. Optics Express 18:19120 19128

119. Ohno Y, Maehashi K, Matsumoto K (2010) Label-free biosensors based on aptamer-modified graphene field-effect transistors. J Am Chem Soc 132:18012-18013

120. Sorgenfrei S, Chiu CY, Gonzalez RL, Yu YJ, Kim P, Nuckolls C, Shepard KL (2011) Label-free single-molecule detection of DNA-hybridization kinetics with a carbon nanotube field-effect transistor. Nat Nanotechnol 6:126-132

121. Sirringhaus H, Kawase T, Friend RH, Shimoda T, Inbasekaran M, Wu W, Woo EP (2000) High-resolution ink-jet printing of allpolymer transistor circuits. Science 290:2123-2126

122. Arbat A, Edqvist E, Casanova R, Brufaua J, Canals J, Samitier J, Johansson S, Diéguez A (2009) Design and validation of the control circuits for a micro-cantilever tool for a micro-robot. Sensor Actuat A Phys 153:76-83

123. Iwata F, Mizuguchi Y, Ozawa K, Ushiki T (2010) Operation of self-sensitive cantilever in liquid for multiprobe manipulation. Jpn J Appl Phys 49:08LB14/1-08LB14/5

124. Sokolov AN, Roberts ME, Johnson OB, Cao Y, Bao Z (2010) Induced sensitivity and selectivity in thin film transistor sensors via calixarene layers. Adv Mater 22:2349-2353

125. Someya T, Sekitani T, Iba S, Kato Y, Kawaguki H, Sakurai T (2004) A large-area, flexible pressure sensor matrix with organic field-effect transistors for artificial skin applications. Proc Natl Acad Sci USA 101:9966-9970

126. Seena V, Nigam A, Pant P, Mukherji S, Ramgopal Rao V (2011) Organic cantifet: a nanomechanical polymer cantilever sensor with an integrated OFET. J Microelectromech Syst (in press) 